\title{
Article \\ Combining Tracking and Remote Sensing to Identify Critical Year-Round Site, Habitat Use and Migratory Connectivity of a Threatened Waterbird Species
}

\author{
Nyambayar Batbayar ${ }^{1,+} \oplus$, Kunpeng $\mathrm{Yi}^{2, *}{ }^{2, \dagger}$, Junjian Zhang ${ }^{2}$, Tseveenmyadag Natsagdorj ${ }^{1}$, Iderbat Damba ${ }^{3}$, \\ Lei Cao ${ }^{2,4}$ and Anthony David Fox ${ }^{5}$ (i) \\ 1 Wildlife Science and Conservation Center of Mongolia, Union Building B-701, Unseco Street, \\ Ulaanbaatar 14210, Mongolia; nyambayar@wscc.org.mn (N.B.); tseveen@wscc.org.mn (T.N.) \\ 2 State Key Laboratory of Urban and Regional Ecology, Research Center for Eco-Environmental Sciences, \\ Chinese Academy of Sciences, Beijing 100085, China; junjianzhang@rcees.ac.cn (J.Z.); leicao@rcees.ac.cn (L.C.) \\ 3 Institute of Biology, Mongolian Academy of Sciences, Ulaanbaatar 13330, Mongolia; iderbat_d@mas.ac.mn \\ 4 University of Chinese Academy of Sciences, Beijing 100049, China \\ 5 Department of Ecoscience, Aarhus University, 8000 Aarhus, Denmark; tfo@ecos.au.dk \\ * Correspondence: kpyi@rcees.ac.cn \\ + Nyambayar Batbayar and Kunpeng Yi contributed equally to this work.
}

Citation: Batbayar, N.; Yi, K.; Zhang, J.; Natsagdorj, T.; Damba, I.; Cao, L.; Fox, A.D. Combining Tracking and Remote Sensing to Identify Critical Year-Round Site, Habitat Use and Migratory Connectivity of a Threatened Waterbird Species. Remote Sens. 2021, 13, 4049. https://doi.org/10.3390/ rs13204049

Academic Editors: Nicholas Coops, Grant Connette and David Thau

Received: 1 September 2021

Accepted: 7 October 2021

Published: 11 October 2021

Publisher's Note: MDPI stays neutral with regard to jurisdictional claims in published maps and institutional affiliations.

Copyright: (c) 2021 by the authors. Licensee MDPI, Basel, Switzerland. This article is an open access article distributed under the terms and conditions of the Creative Commons Attribution (CC BY) license (https:// creativecommons.org/licenses/by/ $4.0 /)$.
Abstract: We tracked 39 western flyway white-naped cranes (Antigone vipio) throughout multiple annual cycles from June 2017 to July 2020, using GSM-GPS loggers providing positions every 10-min to describe migration routes and key staging areas used between their Mongolian breeding and wintering areas in China's Yangtze River Basin. The results demonstrated that white-naped cranes migrated an average of $2556 \mathrm{~km}( \pm 187.9 \mathrm{SD})$ in autumn and $2673 \mathrm{~km}( \pm 342.3)$ in spring. We identified 86 critical stopover sites that supported individuals for more than 14 days, within a $100-800 \mathrm{~km}$ wide migratory corridor. This study also confirmed that Luan River catchment is the most important staging region, where white-naped cranes spent $18 \%$ of the annual cycle (in both spring and autumn) each year. Throughout the annual cycle, $69 \%$ of the tracking locations were from outside of the currently protected areas, while none of the critical staging areas enjoyed any form of site protection. We see further future potential to combine avian tracking data and remote-sensing information throughout the annual range of the white-naped crane to restore it and other such species to a more favourable conservation status.

Keywords: GPS telemetry; Antigone vipio; migration phenology; movement ecology; stopover site; white-naped crane

\section{Introduction}

Long distance avian migration has long been a source of fascination for humans. However, as habitat loss and climate change disrupt the progress of particularly threatened migratory waterbirds, an understanding of species breeding and wintering distributions, migration routes and critical staging areas, food supply and habitat utilization is becoming fundamental to our ability to safeguard the future viability of critical populations [1-4]. Technological advances now provide us with telemetry devices that, when deployed on birds, remotely monitor their activity and environmental variables while simultaneously recording their latitude, longitude and altitude to within a few metres' accuracy in real time as they cross oceans, forests, deserts, and mountainous terrain, transmitting data remotely via mobile telephone networks [5]. Data from such fine-scale GPS tracking loggers, coupled with remote sensing tools provide the level of detail needed to identify and characterize temporal patterns in space-use by birds and reveal the critical habitats they use at all stages throughout their annual cycle [6]. Combining these new methods enables researchers to obtain detailed bird movement data across large spatial and temporal scales, contrasting 
short, repeated movements between roosting sites and feeding areas with long-distance migration episodes [7]. Linking the capabilities of Earth observation datasets with such fine scaled individual movement patterns now offers ecologists, wildlife managers, and conservation practitioners an unprecedented opportunity to collect and assess spatially explicit movement data from individual birds over large geographic areas, at regular time intervals, and in near real-time [8,9]. Many satellite-derived remote-sensing data sets have become accessible free of charge, providing new opportunities to develop models to predict how individual birds and ultimately species will respond to seasonal or climatic changes based on the combination of bird telemetry data and remote-sensing data [10].

In this study, we use such an approach to improve our understanding of the conservation needs of the white-naped crane, Antigone vipio, a species listed as IUCN Red List category Vulnerable, with an estimated 500-1000 birds wintering in China and 5750 in Korea and Japan [11]. The species is thought to comprise two separate biogeographical populations. The western population breeds in north-eastern Mongolia, north-eastern China and the Chita and Daurian regions of south-eastern Russia (Fujita et al. 2004). Cranes from this breeding area were thought to winter exclusively in the Yangtze River floodplain of China, probably mainly at Poyang Lake [12] (although we completely lacked data from Mongolian breeding areas to confirm this). The eastern population breeds mostly in Russia along the Amur, Argun and Ussuri Rivers, as well as the Khinganski and Khankaiski State Nature Reserves, and winters on the Korean Peninsula and Kyushu, Japan [13,14]. While the eastern population is currently thought to be increasing, the western population is declining [15]. The Chinese wintering population is largely confined to Poyang Lake, where fluctuating numbers have declined from mean maximum counts of 2278 between 1996 and 2004 ( $n=8$ counts in this period) to 1167 during 2005 to $2012(n=6)$ [16]. Eastern Mongolian breeding census data also show declines in the last ten years, confirming that this flyway population may be experiencing serious problems throughout the annual cycle to which the eastern population is not currently exposed [16]. Despite the conservation efforts that have been taken both at wintering and breeding areas, we know little about their migration routes, stopover sites and habitats used during migration, or anything about the level of threats to the species at other points in the annual cycle. Previous studies have called for the improvement of our knowledge base relating to where, when, and why white-naped cranes move between key areas, their habitat use, home range size, migration phenology and the biotic and abiotic factors that drive their distributions, knowledge upon which to base their effective conservation management $[15,17]$. Thanks to recent advances in tracking and remote sensing technology, we are now able to deploy small telemetry devices to derive such information and relate their movements to globally mapped habitat types at spatial scales from a few metres to thousands of kilometres.

Here, we report on our use of GPS tracking of white-naped cranes to achieve a number of objectives. Firstly, we seek to gain further evidence that the white-naped cranes breeding in Mongolia winter in China and are separate from those that winter in Korea and Japan. Secondly, we wish to describe their migration patterns, including timing and nature of the autumn and spring migration episodes and identify specific migration routes and critical stopover areas. Finally, and most importantly, we combine crane tracking and remote data to identify habitat use and the use of protected area by cranes through their entire annual cycle to determine the conservation priorities and current gaps in current protected areas network for white-naped crane to improve its currently unfavourable conservation status.

\section{Materials and Methods}

We captured and instrumented 39 white-naped cranes at nest sites on their breeding grounds in the Khurkh and Khuiten River Valleys and the Kherlen River Valley in eastern Mongolia in summer 2017, 2018 and 2019 during their flightless periods. Fledging juveniles were caught in their hatching year (hereafter "HY") before their wings were fully grown, while adults were caught during moult of their plumages before regaining the power of flight. Capture teams approached by stealth and ran down flightless cranes 
by active pursuit. Birds were fitted with $35 \mathrm{~g}$ waterproof leg-mounted solar powered Ornitela L-40 GPS/GSM logging transmitters (hereafter "loggers" $64 \times 35 \times 32 \mathrm{~mm}$, which contributed an average of an extra $0.83 \%$ of the body mass of instrumented birds, Table S1). We deployed loggers on 19 HY birds in 2017 (Figures S2-S20), 3 adults in 2018 (Figures S21-S23) and 17 birds in 2019 (Figures S24-S40; 12 HY, 5 adults, see Table S1 in Supporting Information). All loggers were fitted in less than a minute and birds were released within 30-40 min at the capture site after loggers were deployed, after careful observation to make sure that the birds were not suffering from capture myopathy, trauma or stress associated with capture and handling. The loggers recorded GPS coordinates, flight altitude, speed, direction, horizontal dilution of precision, and battery voltage. Tracking data were uploaded via the GSM/GPRS/3G telecommunication networks and downloaded from Ornitela's website (https:/ / www.ornitela.com/ accessed on 31 August 2021). Three external solar panels recharged onboard batteries and low power consumption allowed base rate collection of positional data (latitude/longitude) at 10-min intervals when operating between -20 to $+70{ }^{\circ} \mathrm{C}$ and storage of 1000 positions without recharge. This duty cycle generated the positions of each crane throughout their migration episodes between wintering and summering quarters, where their positions were also monitored at the same frequency. We accumulated data from the loggers over the course of their lifetimes (i.e., until their malfunction on active birds) or until the death of the birds (since loggers also incorporated movement sensors, uploaded data from which indicated when the device ceased to show active movement, see Table S1 for individual details). The collected data used in this study originate from between 1 August 2017 and 6 July 2020. In this way, we derived data from individuals that varied in extent between 80 and 1054 days (average $449 \pm 313$ days). Invalid positional data were filtered out to remove rare longitudes $>180^{\circ}$ and latitude $>90^{\circ}$. We calculated great-circle-distances, using the "haversine method" [18], between adjacent GPS locations using the distHavesine function in the geosphere package [19] in R (R Development Core Team 2017).

We used the methods described in previous studies [20-23] to analyse crane movements, differentiating sections of the tracking paths into periods of migration between stopover/staging, breeding or wintering areas, where tracked individuals would still diurnally commute between feeding and roosting areas, but not undertake long, largely unidirectional movement (for further details see Appendix S1 in Supplementary Materials). Based on these segmentations and classifications, we defined 11 migration parameters to describe the specific cranes' movement patterns and features of migration (Table 1) from the birds for which we derived full information over an entire migration episode (i.e., birds for which continuous movement data were available from summer to wintering grounds or vice versa). All data are expressed as means \pm SD. The loggers permit the fine-scale high-precision tracking of birds to identify areas subject to disproportionate high use by tagged birds. We applied kernel density estimation (KDE) to describe the density of cumulative bird use in two-dimensional space and to identify bird movement corridors during the course of their annual migration cycle. We calculated a magnitude-per-unit area from GPS location or movement trajectory features using a kernel function to fit a smoothly tapered surface to each GPS point or polyline. After Silverman (1986), we estimated the bivariate density at a given grid point $x$ as:

$$
\hat{p}(x)=\frac{1}{n h^{2}} \sum_{i=1}^{n} K\left(\frac{d_{i}(x)}{h}\right)
$$


Table 1. Migration parameters of white-naped cranes Antigone vipio used in this analysis and their precise definitions as applied to the data analysis presented here.

\begin{tabular}{|c|c|c|}
\hline Parameter & Definitions & Reference \\
\hline Departure date & $\begin{array}{l}\text { The date of the first position when a bird } \\
\text { left wintering/moulting/breeding sites } \\
\text { and was judged by the methods } \\
\text { described in the text to have acquired } \\
\text { flight status. }\end{array}$ & [21] \\
\hline Arrival date & $\begin{array}{l}\text { The date when a bird was determined to } \\
\text { have arrived at wintering or breeding } \\
\text { sites, based on the methods described in } \\
\text { the text to qualify as "non-flight" status } \\
\text { after a period of flight. }\end{array}$ & [21] \\
\hline Migration duration & $\begin{array}{l}\text { The time a bird took to travel (including } \\
\text { stopovers) between the last summering } \\
\text { site and first wintering site (autumn } \\
\text { migration) or between the last wintering } \\
\text { and the first summering site (spring } \\
\text { migration). }\end{array}$ & [22] \\
\hline Migration distance & $\begin{array}{l}\text { The cumulative travel distance between } \\
\text { all adjacent GPS locations which were } \\
\text { defined as "flight" status during } \\
\text { migration, the distance between two } \\
\text { adjacent GPS locations. }\end{array}$ & {$[22,23]$} \\
\hline Migration speed & $\begin{array}{l}\text { The migration speed is defined as the } \\
\text { total distance (in kilometres) divided by } \\
\text { the total duration of migration in days. }\end{array}$ & [24] \\
\hline Travel speed & $\begin{array}{l}\text { The daily travel speed is the migration } \\
\text { distance divided by total travel days. }\end{array}$ & [24] \\
\hline Travel duration & $\begin{array}{l}\text { Travel days is the total duration of } \\
\text { migration (days) minus stopover days. }\end{array}$ & [24] \\
\hline Stopover duration & $\begin{array}{l}\text { The sum of all days spent at all stopover } \\
\text { sites during each migration season. }\end{array}$ & [24] \\
\hline Migration bout length & $\begin{array}{l}\text { Calculated as the migration distance } \\
\text { divided by the number of flight legs } \\
\text { during each migration season. }\end{array}$ & [25] \\
\hline Number of Stopovers & $\begin{array}{l}\text { Sites where birds rested and fed during } \\
\text { migration for more than } 2 \text { days. }\end{array}$ & [23] \\
\hline Straight index & $\begin{array}{l}\text { When the goal is located at a finite } \\
\text { distance D from the starting point, and } \\
\text { the animal reaches it after having } \\
\text { travelled some variable path length L; the } \\
\text { orientation efficiency is often empirically } \\
\text { measured as the ratio D/L; referred to as } \\
\text { the straightness index. }\end{array}$ & {$[26,27]$} \\
\hline
\end{tabular}

Here, $K(\cdot)$ is a kernel, $h$ is the bandwidth or smoothing parameter, and $\operatorname{di}(x)$ is the distance between the grid point $x$ and the $i$-th visited location $X i=(x i, y i) \in X$. The most usual choice for $K(\cdot)$ is a radially symmetric unimodal probability density function such as the bivariate normal density.

By identifying bird activity spaces of any nature, and estimating corresponding anchor locations, KDE is preferable to ellipse and minimum convex polygon methods [28]. In addition, we applied the tracking analyst toolbox of ArcGIS 10.7 software to calculate bird movements computed from the distance between successive time stamped positions along a track, using "Track Intervals To Line" function to generate bird movements in terms 
of distance, duration and speed (see Figure S1 in Supporting Information). We grouped all remaining adjacent non-sedentary segments as migration segments. Following the modified methods of $[29,30]$, we segmented tracking paths into periods of direct flight movements and stopovers by using the first passage time (FPT) method [31]. FPT estimates the time taken from a predefined starting location for each crane to move a given distance away (defined as a circle of given radius around the starting location) by applying the penalized contrast method [32]. The FPT generates the minimum time before a crane crosses a given radius across its path; this value is low when actively flying long distance on migration, high when it remains within a restricted area. The shift between adjacent sequences at breeding, staging and wintering areas (high FPT) and bouts of direct flight movement (true migration, low FPT) identify departure and arrival times/dates during each sequential migration bout. We set the range for optimal FPT radius to be a geometric sequence of 500 steps from 2.5 to $50 \mathrm{~km}$ and applied this as a hierarchical segmentation process with up to 4 iterations for each segment or until no further segmentation was forthcoming [23]. For the purposes of this study, we identified stopover sites as all positions where individuals remained for more than 2 days. Sites where cranes remained over 14 days were arbitrarily recognized as critical stopover sites. In order to exclude positional fixes during stopovers when the bird was actually flying, we only retained GPS locations within stopover, summering and breeding areas where the velocity between adjacent points was less than $1 \mathrm{~km} / \mathrm{h}$. We used these points as the basis for assigning bird positions to habitat types (below) using cumulative percentages of land use types to characterise their habitat use during these three periods of the annual cycle.

To analyse habitat use by cranes, we applied a $10 \mathrm{~m}$ spatial resolution land cover (classified into 10 major land use cover types, including Cropland, Forest, Grassland, Shrubland, Wetland, Water, Tundra, Impervious surface, Bareland and Snow/Ice, of which 8 were relevant to this study) dataset (FROM-GLC10) as a GIS layer. This classification is based upon Sentinel-2 imagery data analysed using the freely accessible data and the programming environment within Google Earth Engine [33]. We then overlaid positions from the raw crane tracking data on the habitat maps (for an example see Figure 4C,D). We used simple $\chi^{2}$ tests (programmed in Excel) to test for seasonal differences in the habitat use by comparing seasonal (summer, staging or winter) percent habitat use of key habitats types (constituting more than $5 \%$ use by cranes) with the mean percentage use for the entire annual cycle combined for each season/habitat.

To determine the effectiveness of the current site safeguard network to protect areas used most intensively by white-naped cranes throughout their annual cycle, we also overlaid all the raw crane tracking data on the combined China's National Nature Reserve (NNR) data (http:/ /www.papc.cn/html/folder/13100752-1.htm accessed on 31 August 2021) and World Database on Protected Areas (WDPA) data (https:/ / www.iucn.org/theme/protected-areas/ our-work/quality-and-effectiveness/world-database-protected-areas-wdpa accessed on 31 August 2021) layers in ArcGIS 10.7.

\section{Results}

\subsection{Migration Patterns}

Data from full migration cycles from the loggers during 2017-2020 showed that all 39 tagged white-naped cranes migrated an average of $2556 \mathrm{~km}( \pm 187.9 \mathrm{SD})$ in autumn and $2673 \mathrm{~km}( \pm 342.3)$ in spring (Table 2$)$ between their breeding grounds in Mongolia and the wintering grounds exclusively in the Yangtze River Basin, China (shown systematically in Figure 1). Tagged white-naped cranes spent an average of 150 days $( \pm 20)$ on their eastern Mongolian breeding grounds, departing on average on 5 October ( \pm 10 days), migrating for an average of 35 days $( \pm 14)$. The birds arrived to the Yangtze River Floodplain winter quarters (all except one at Poyang Lake) from late October to early November (mean 9 November \pm 10 days), where they spent an average of 120 days ( \pm 15$)$. Spring migration departure was highly synchronized from all wintering sites around 9 March ( \pm 5 days, see Figure 1). Tagged white-naped cranes spent almost two months (49 days \pm 15 ) on spring 
migration en route to the breeding grounds, where they arrived on average on 26 April ( \pm 14 days, see Table 2 ).

Table 2. Statistical comparison of the key spring and autumn migration parameters of white-naped cranes Antigone vipio $(n=39)$ based on Student $t$-tests with unequal variances (within an Excel environment).

\begin{tabular}{cccccc}
\hline Parameter & $\begin{array}{c}\text { Mean Value } \pm \text { SD for } \\
\text { Autumn Migration }\end{array}$ & $\begin{array}{c}\text { Mean Value } \pm \text { SD for } \\
\text { Spring Migration }\end{array}$ & $D f$ & $\boldsymbol{t}$-Value \\
\hline Migration duration (Days) & $34.7 \pm 14.2$ & $48.8 \pm 15.4$ & 75.6 & 3.7 & $<0.001$ \\
Migration distance (km) & $2555.9 \pm 187.9$ & $2673.2 \pm 342.3$ & 50.2 & 1.9 & 0.062 \\
Migration speed (km/Days) & $86.4 \pm 40.9$ & $60.9 \pm 22.2$ & 39.3 & -3.0 & 0.004 \\
Travel speed (km/Days) & $310.6 \pm 100.0$ & $296.2 \pm 88.1$ & 47.7 & -0.7 & 0.478 \\
Travel duration (Days) & $9.1 \pm 3.7$ & $9.9 \pm 4.0$ & 46.0 & 1.0 & 0.339 \\
Stopover duration (Days) & $25.5 \pm 13.4$ & $38.8 \pm 14.8$ & 77.7 & 3.6 & $<0.001$ \\
Migration bout length (km) & $1013.3 \pm 224.2$ & $1045.0 \pm 343.3$ & 72.6 & 1.6 & 0.107 \\
Number of stopovers & $1.6 \pm 0.6$ & $1.8 \pm 0.9$ & 73.2 & -0.2 & 0.837 \\
Straightness index & $0.9 \pm 0.1$ & $0.8 \pm 0.1$ & 80.0 & -2.1 \\
\hline
\end{tabular}

Migration trajectories of the white-naped cranes are shown in Figure 2 but are summarized using KDE in Figure 3, highlighting a relatively narrow (about $100 \mathrm{~km}$ wide) corridor (Figure 3) during both the spring and autumn seasons, interrupted by periods spent at stopover sites (see below). The migration corridor is enlarged by a few individuals to almost $800 \mathrm{~km}$ between the Luan He catchment and breeding grounds (Figure 2). There was no significant difference between autumn (9 days \pm 3.7 ) versus spring (10 days \pm 4.0 ) travel duration, yet autumn migration duration (35 days \pm 14 ) was significantly shorter than in spring ( $49 \pm 15.4$, Table 2$)$. This was the result of significantly longer spring stopover duration (39 days \pm 14.8 versus 26 days \pm 13.4 ) over the same distance travelled (Table 2), there being no differences in migration bout length or numbers of stopovers taken in autumn and spring (Table 2). None of the white-naped cranes which finished a full migration cycle returned to their precise point of capture, but all returned to the species' core breeding region in the Khurkh and Khuiten River Valleys, Onon, Kherlen, and Ulz Rivers following their first and subsequent winters.

\subsection{Migration Routes and Critical Stopover Areas}

We identified several important stopover sites along the entire flyway (Figures 2 and 3), particularly in the first major stopover complex, situated in the Luan River catchment (part of the larger Luan He catchment) in Duolun and Guyuan counties (Figures 2 and 3). The cranes subsequently used the Chaobai River basin, the Miyun Reservoir in Beijing, the Beidagang Reservoir in Tianjin and the Shandong freshwater wetlands in the Yellow River Delta. All but one of the tagged cranes showed wintering site loyalty to Poyang Lake in the Yangtze River Floodplain (Figure 2). The tracking data identified 86 identified critical stopover sites which supported individuals for more than 14 days, 38 sites during spring migration, 48 during autumn migration (Figure 2 and Table S2), all distributed Beidagang Reservoir in Tianjin. During spring and autumn migration, no tagged white-naped cranes made prolonged stops ( $>15$ days) in China between the Yangtze and Yellow Rivers (Figure 2). Seven birds used Bohai Bay stopover sites on spring migration, but all 39 birds made prolonged stops in the Luan River catchment. The results also demonstrate that all tagged individuals followed autumn migration routes closer to the coastal zone than in spring, when birds followed routes further inland between the Yangtze and Yellow Rivers, when the routes deviated more from following a straight course and were significantly different to those in autumn (Table 2). Both KDE and FTP results confirmed that the Luan River catchment contains the most important stopover sites for Mongolian-Chinese white-naped cranes. Among the 86 identified critical stopover sites, 65 were located there (29 out of 38 sites in spring, 36 out of 48 in autumn, Figure 2). Overall, the tagged cranes spent $18 \%$ of the annual period staging in the Luan River catchment, compared to just 3\% time in the Beidagang Reservoir and Yellow River Delta wetlands, the next most important 
staging areas for the species (Figure 3). The combination of tracking and remote sensing data showed cranes used Luan River natural wetlands and adjacent croplands (Figure 4), confirmed by our own October 2020 ground surveys that found that cranes mainly foraged on oats (Avena sativa and A. chinesis) and maize (Zea mays) also as recorded by [34]. All cranes used the Luan River catchment heavily in both spring and autumn, with concentrated use in six key regions (see Figure 4A,B). Thee cranes spent more time on croplands in the wintering grounds, which in the case of Poyang Lake individuals was mainly rice paddy fields (also established by field survey team observations in winter 2020/21).

\subsection{Crane Habitat Use}

On average, tagged white-naped cranes were recorded as spending $44 \%$ of their time in grassland, over $34 \%$ of their time in wetlands and water areas combined, and nearly $21 \%$ of their time in croplands, although this varied considerably between seasons. As for the breeding grounds, cranes mostly made use of grassland (89\%), also used to a major degree during stopovers $(69 \%$, complemented by $23 \%$ on cropland) but grassland was hardly used at all in winter, when they divided their time between water and wetlands (67\%) with less (21\%) time in cropland (Table 3). The tagged birds used croplands, wetlands and water significantly more in winter than on average throughout the entire year, while they used grasslands significantly more than average during staging stopovers, when they used wetlands and open water areas less than average. Regarding the breeding areas, due to a lack of extensive croplands, these were used significantly less used than on average for the rest of the year, while grasslands and open water were used more ( $p<0.01$ in case cases).

\subsection{Protected Area Status of Crane Sites}

Overlaying crane positions on the protected area maps in GIS layers determined that, on average, $69 \%$ of tracking locations throughout the annual cycle fell within areas unprotected by the current conservation site safeguard network. Regarding the staging areas, almost no sites $(99.99 \%)$ used by the cranes enjoyed any level of protected status. Regarding the breeding areas, $85 \%$ of positions from tagged cranes fell outside the designated protected areas in Mongolia. Because of the major confinement almost exclusively to Poyang Lake (with the single bird at Dongting lake, both large national nature reserves), in China, $62 \%$ of positions from tagged birds originating from within statutory protected sites. 


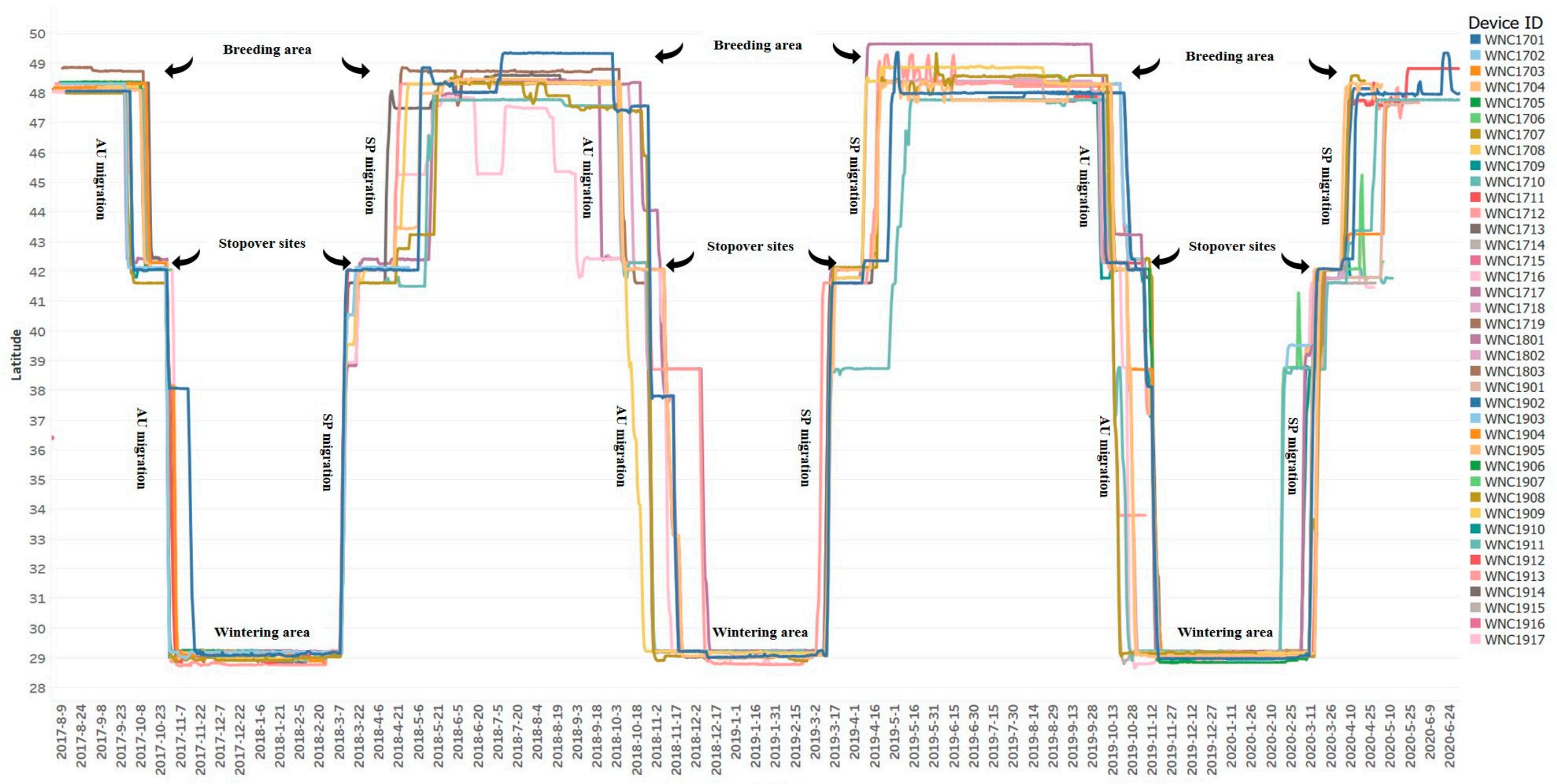

Date

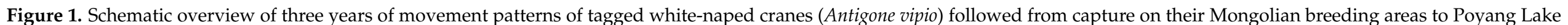

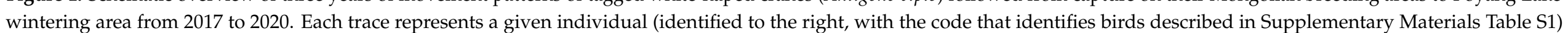
illustrated for the period for which it generated data. 

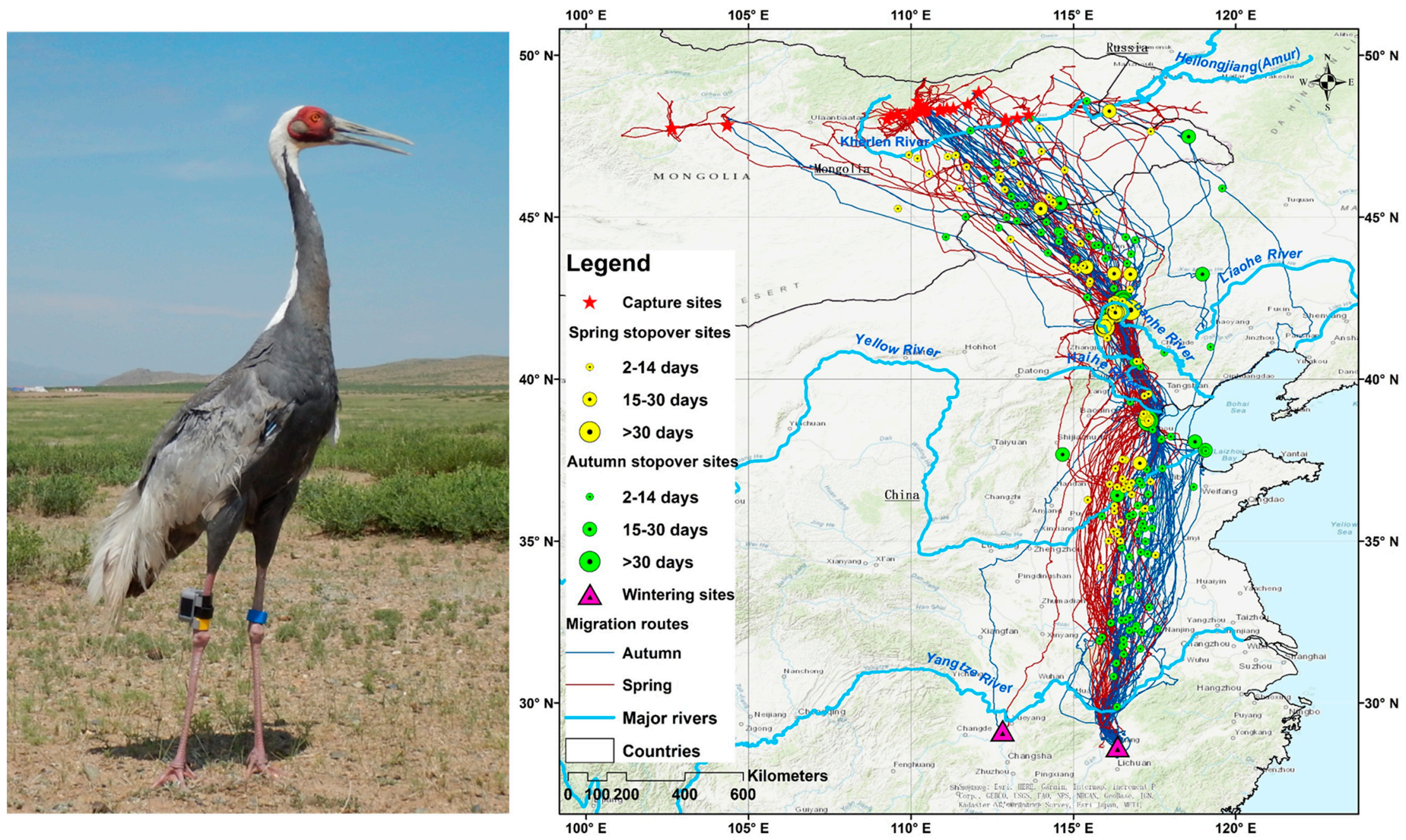

Figure 2. Spring (red) and autumn (blue) migration routes of white-naped cranes (Antigone vipio) and their stopover sites (spring yellow, autumn light green). Relative size of stopover site symbols reflect individual lengths of stay. The white-naped crane was photographed by Dr. Iderbat Damba on 6 July 2019 at Ugii Lake $\left(47.755188^{\circ} \mathrm{N}, 102.652021^{\circ} \mathrm{E}\right)$ in Mongolia. 


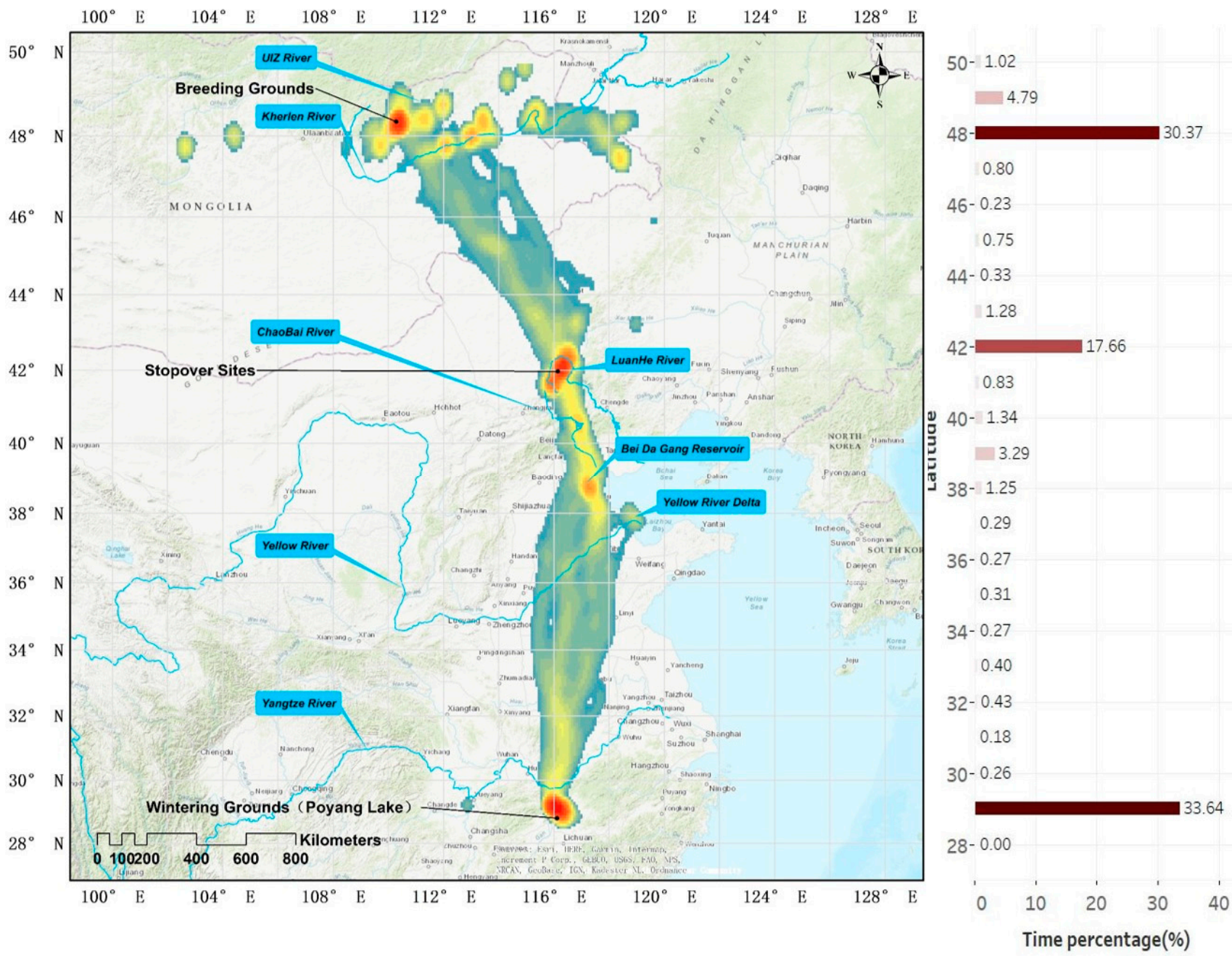

Figure 3. Mapping of white-naped cranes (Antigone vipio) migration corridors, based on Kernel Density Estimation summarization of tracking data from 39 tracked individuals throughout the annual cycle summed over two years. Orange to red colour indicate highest intensity of use, green to yellow lowest. Right side of the figure shows time spent in each latitude zone.

Table 3. Summary mean seasonal habitat use of Mongolian-Chinese white-naped cranes Antigone vipio.

\begin{tabular}{ccccc}
\hline Habitat Types & Breeding & Staging Stopover & Wintering & Total \\
\hline Cropland & $0.65 \%$ & $22.63 \%$ & $32.30 \%$ & $20.72 \%$ \\
Forest & $0.04 \%$ & $0.77 \%$ & $0.03 \%$ & $0.24 \%$ \\
Grassland & $89.29 \%$ & $68.62 \%$ & $0.25 \%$ & $44.29 \%$ \\
Wetland & $4.65 \%$ & $1.84 \%$ & $17.76 \%$ & $9.65 \%$ \\
Water & $3.56 \%$ & $5.52 \%$ & $49.64 \%$ & $24.41 \%$ \\
Impervious surface & $0.19 \%$ & $0.44 \%$ & $0.02 \%$ & $0.19 \%$ \\
Bare substrate & $1.55 \%$ & $0.16 \%$ & $0.00 \%$ & $0.48 \%$ \\
Snow $/$ ice & $0.07 \%$ & $0.00 \%$ & $0.00 \%$ & $0.02 \%$ \\
\hline
\end{tabular}



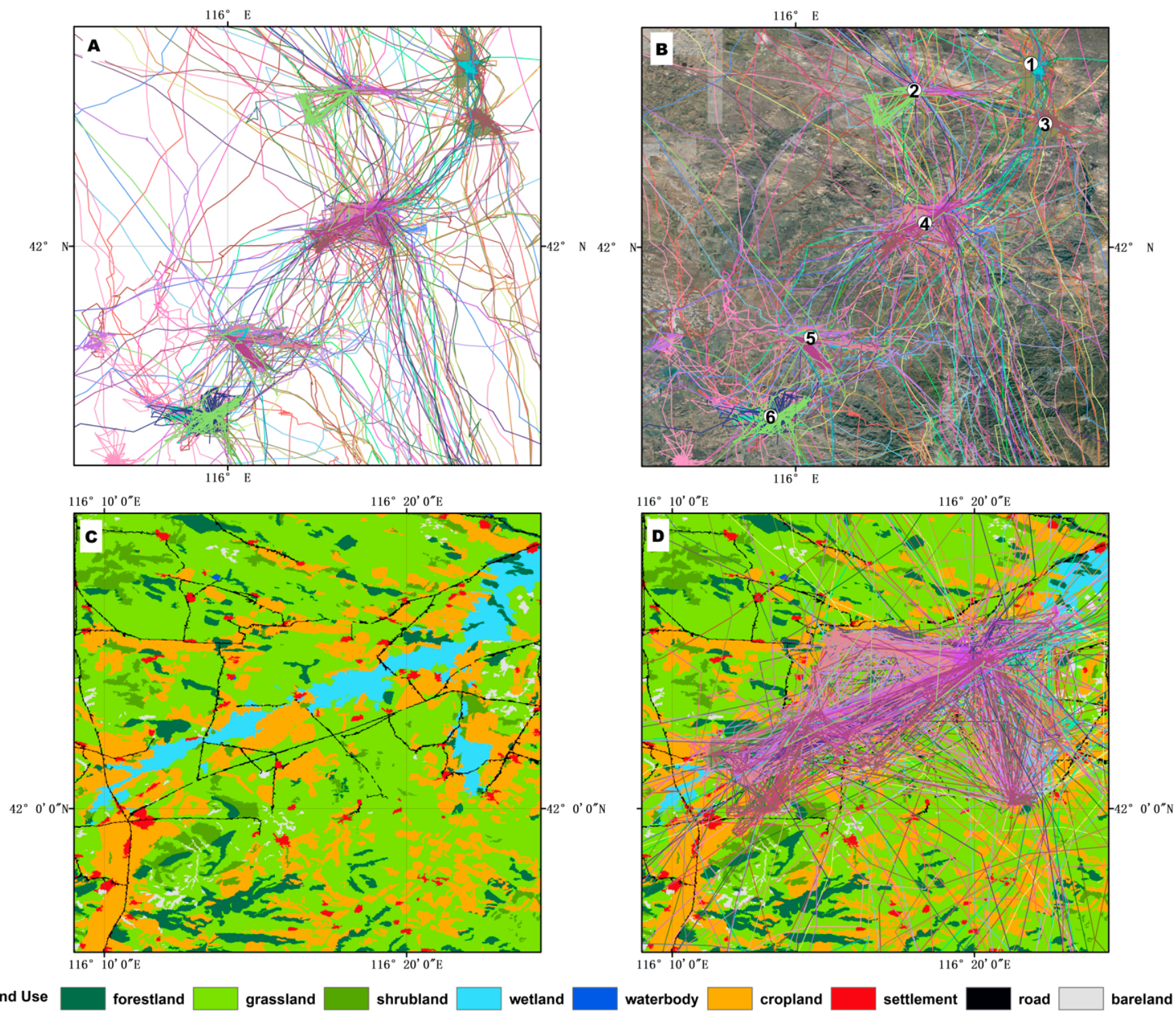

Land Use

forestland grassland shrubland wetland waterbody bareland

Figure 4. Movements and distribution of Mongolian-Chinese white-naped cranes Antigone vipio at their major stopover sites in the Luan River catchment. (A) shows movement trajectories for 39 birds in different colours; (B) shows the location of six critical sites distribution in the Luan River catchment overlaid on a satellite image; $(\mathbf{C})$ is a more detailed land use map for critical site No.4 identified in (B); (D) shows movement trajectories overlaid on the land use map (see Table 3 for habitat use at this time).

\section{Discussion}

Based on our small sample of tagged birds, our results confirm that many whitenaped cranes from the important breeding concentrations in the Ulz and Kherlen River basins of Eastern Mongolia, as well as birds captured further west in central Mongolia, overwinter in the Yangtze River Floodplain in China. This confirms the general pattern shown by earlier satellite tracking of white-naped cranes from their breeding grounds in eastern Russia, which also wintered there $[13,14]$. Those authors showed that cranes from the western breeding areas (in the Daursky Nature Reserve $\left(50^{\circ} \mathrm{N}, 115^{\circ} \mathrm{E}\right)$ in Chita near to the eastern Mongolia border) tended to winter in Poyang Lake, China, while those marked further east $\left(49^{\circ} \mathrm{N}, 127^{\circ}-129^{\circ} \mathrm{E}\right)$ wintered in Japan. These results contribute to confirming the longitudinal division between the two wintering populations and suggest that the birds breeding in Mongolia and adjacent areas of the Daurian region of the Russian Federation are those wintering in China, currently suffering unfavourable conservation 
status compared to those wintering in Japan (where numbers are stable or increasing). However, we require much further marking and tracking of birds from these two flyways before we can determine the degree of connectivity between what begins to appear to be relatively discrete flyways.

The results also indicated that the Daurian white-naped cranes make stopovers over several weeks in the Luan River catchment (a tributary of Luan He River) in Duolun County, Inner Mongolia (China) in both autumn and spring migration. Our follow-up ground observations found over 200 individuals at this site on 1 May 2018 and nearly 1000 individuals on 1 October 2018, respectively, confirming the importance of this area to white-naped cranes staging here before continuing to the breeding grounds. The wetlands in this area begin to melt around 15 April and the lakes are completely free of ice at the beginning of May. This suggests this area, together with the other sites identified as critical for supporting individual cranes for more than two weeks in spring, should be the subject of detailed investigations on the ground to identify key feeding areas and habitats, and their associated safe overnight roosting areas. This is important from a conservation perspective, to ensure the birds enjoy adequate habitat safeguards and sympathetic management (including protection from disturbance and the provision of sacrificial crops and grassland areas on farmland used by cranes at critical periods) in these areas during these important periods for fat and nutrient accumulation, in the prelude to reproduction. This is especially important given the complete lack of nature protection areas designated in the area, which leaves the population totally unprotected during the two crucial staging periods of the annual cycle, but especially in spring.

The results showe that Mongolian-Chinese white-naped cranes show an "inverted triangle" migration pattern (Figure 2). Data from the white-naped cranes exclusively marked on the breeding areas mostly wintered at Poyang Lake (only one bird in one year wintered in Dongting Lake) in the Yangtze River Floodplain, contributing to the evidence of the increasing importance of this site to the flyway population as a whole. Although formerly more widespread in the Yangtze River Floodplain [35], like so many other wintering waterbird species there [36-39], the white-naped crane has increasingly concentrated the greater proportion of its wintering numbers at this site. In comparison with their broad summering area in Mongolia, their wintering area is highly concentrated and increasingly limited to Poyang Lake, with annual waterbird count data confirming very few birds were sporadically distributed through other wetlands (such as at Dongting, Caizi and Wuchang Lakes). This confirms the contraction of the white-naped crane wintering area to a few surviving lakes which remain currently free from dams, compared to previous extent of its broad wintering range throughout the Yangtze River Floodplain, a contraction which has occurred in just the last two decades. As the most outstanding wetland National Nature Reserve in China, Poyang Lake enjoys some of the highest levels of nature protection anywhere in the country [40], so the increasing concentration of white-naped cranes at the site is potentially proof of the effectiveness of the nature conservation management and protection at the site. However, Poyang Lake also continues to suffer severe multiple environmental pressures. These include sand dredging [41], increased shipping activity, habitat loss, upstream damming and pollution of catchment water quality by industry and agriculture, as well as being under constant threat of hydrological damage from the construction a major dam to isolate it from the main Yangtze River [42-44]. Interrogation of thousands of satellite images using machine learning algorithms identified 1092 vessels extracting sediments within Poyang Lake, illegal activities that are reshaping water channels and profoundly adversely impacting upon wintering swan geese (Anser cygnoides) another endemic Chinese wintering waterbird species that increasingly relies on the site for its winter quarters as numbers decrease elsewhere $[45,46]$. Both species are highly reliant upon undisturbed sediments and hydrology to gain access to food items buried in sediments in shallow waters at the site during winter water recession at Poyang Lake $[47,48]$. We are therefore keen to continue the analysis of these data on the movements of white-naped cranes within the site to add to the body of knowledge about key habitats used by the 
species throughout the winter under different hydrological regimes to better safeguard the species at this site.

Our findings also pinpoint the need for transnational cooperation in those key sites between Mongolia and China. While it was disappointing to find only $15 \%$ of marked cranes returned to summering areas in Mongolia that enjoy any form of site-protection, we at least now possess this information and can use it to recommend the areas used by the greatest numbers of cranes to be ground surveyed to confirm their importance. Ultimately, this combined information can be used to protect these sites where appropriate, as part of a coordinated cohesive site safeguard network designed specifically for the species. This is becoming increasingly important as overgrazing by livestock, wetland degradation and fires in the Mongolian steppe region increasingly threaten the integrity of their breeding habitat.

The application of tracking technology also identified the discrete migratory corridors used by the white-naped cranes in the course of their multiple annual migratory cycles, providing new information on their precise migration routes, information that can feed directly into informing large scale terrestrial strategic, regional and local land-use planning. Cranes are large-bodied, less manoeuvrable and relatively low-flying migrants, globally susceptible to collisions with overhead power lines [49-51], airstrikes around airports [52-55] and potentially collisions with wind turbines [56]. We have been able to show that the migration of this species is highly confined in time (short bursts in spring and autumn) and relatively constrained in space (given the migration corridors are narrow compared to broad-front migratory species). Armed with the knowledge we have, we should increasingly incorporate information on their abundance in time and space into conservation decision-making and spatial planning. This is especially the case with regard to the siting of new power lines, wind turbines and airports, to avoid conflict with human safety and economic activities as well as reducing additional mortality to a species with already unfavourable conservation status to safeguard the species for future generations.

\section{Conclusions}

Despite the generation of considerable amounts of new knowledge, we should be prudent about not concluding too much from a relatively limited sample of mostly hatchyear white-naped cranes (we were only able to track eight adult birds), which may not be typical of larger numbers of adult birds, which are the reproductive part of the population. We would especially urge the collection of more data to explain our finding that autumn migration routes were closer to the coastal zone compared to the spring, when cranes travelled further inland in the region between the Yangtze and Yellow Rivers. Our studies also relate to birds caught at a relatively few sites from within an extensive area of the nesting grounds. Hence, there is a need to expand the study to more adult individuals from a greater area of the breeding range to add to our knowledge of flyway definition, important staging areas and the need for conservation management of habitats used by the species. Perhaps most importantly, we also urge more investment in follow-up research on the ground to capitalise on the knowledge presented here about key land use types exploited by white-naped cranes at different times of the annual cycle. There need to be assessments of the levels of sympathetic management of such habitats and site protection, information that is essential if we are to understand more fully the year round pressures on the species and the likely conservation management interventions needed to restore this population to favourable conservation status. Although white-naped cranes now increasingly aggregate at Poyang Lake in the Yangtze River Floodplain, this classically makes the species all the more vulnerable to disease, habitat loss and degradation and human disturbance by the nature of their concentration. Despite the very high level of site protection enjoyed by this, probably China's most outstanding freshwater wetland nature reserve, as discussed above, the site and the species continue to be under threat. This is not least because of the quality and quantity of the water it receives from its catchment outside of the protected areas over which the nature reserve has no control. Our data 
clearly show that at stopover sites, white-naped cranes rely heavily upon cropland, which places them at the mercy of changes in agriculture and land use in the few concentrated staging areas upon which the entire population relies for short critical periods of refuelling along their annual migration corridors. All these areas are in densely human populated areas, where they face threats form overexploitation of wetlands, grazing, harvest activities and changes in agriculture [15,57]. The fact that none of the identified staging stopover areas are currently protected gives considerable cause for concern. We particularly urge initiating investigations to determine natural feeding habitats in these areas, along with safe night-time roosts and farmland areas of outstanding importance to the species to establish a baseline justification for site protection that should underpin the designation of a cohesive network of sites of protected area status to safeguard the entire population throughout the annual cycle. Nevertheless, this study shows how satellite tracking, combined with spatial analyses, can be used to provide the information basis to improve species management and conservation strategies, especially through the identification of habitat use and holes in our current site-safeguard network for threatened species such as the white-naped crane.

Supplementary Materials: Supplementary materials can be found at https:/ / www.mdpi.com/ article/10.3390/rs13204049/s1.

Author Contributions: L.C. and K.Y. conceived and designed the framework of the study and field survey. N.B., T.N. and I.D. conducted bird capture and measurements. K.Y. and N.B. performed analysis with assistance from J.Z., who coded the migration parameters calculation. K.Y., L.C. and A.D.F. wrote the initial draft of the paper, with substantial editorial input from all authors. All authors have read and agreed to the published version of the manuscript. N.B. and K.Y. contributed equally to this work.

Funding: This research was funded by the National Natural Science Foundation of China (Grant No. 31870369 and Grant No. 31970433) and China Biodiversity Observation Networks (Sino BON).

Data Availability Statement: The raw/processed data required to reproduce these findings cannot be shared at this time as the data also form part of an ongoing study.

Acknowledgments: The authors are grateful to the anonymous reviewers for their insightful and helpful comments that have helped to improve the original manuscript. Thanks to the Animal Ethics Committee, Research for Eco-Environmental Sciences, Chinese Academy of Sciences who approved this study and for approval for bird capture and logger deployment in Mongolia obtained from the Ministry of Nature, Environmental and Tourism of Mongolia (permissions 06/2564 and 06/2862).

Conflicts of Interest: The authors declare no conflict of interest.

\section{References}

1. Siegel, R.B.; Taylor, R.; Saracco, J.F.; Helton, L.; Stock, S. GPS-tracking reveals non-breeding locations and apparent molt migration of a Black-headed Grosbeak. J. Field Ornithol. 2016, 87, 196-203. [CrossRef]

2. McGowan, J.; Beger, M.; Lewison, R.L.; Harcourt, R.; Campbell, H.; Priest, M.; Dwyer, R.G.; Lin, H.Y.; Lentini, P.; Dudgeon, C.; et al. Integrating research using animal-borne telemetry with the needs of conservation management. J. Appl. Ecol. 2017, 54, 423-429. [CrossRef]

3. Carter, M.I.D.; Cox, S.L.; Scales, K.L.; Bicknell, A.W.J.; Nicholson, M.D.; Atkins, K.M.; Morgan, G.; Morgan, L.; Grecian, W.J.; Patrick, S.C.; et al. GPS tracking reveals rafting behaviour of Northern Gannets (Morus bassanus): Implications for foraging ecology and conservation. Bird Study 2016, 63, 83-95. [CrossRef]

4. Alerstam, T.; Backman, J. Ecology of animal migration. Curr. Biol. 2018, 28, R968-R972. [CrossRef] [PubMed]

5. Neumann, W.; Martinuzzi, S.; Estes, A.B.; Pidgeon, A.M.; Dettki, H.; Ericsson, G.; Radeloff, V.C. Opportunities for the application of advanced remotely-sensed data in ecological studies of terrestrial animal movement. Mov. Ecol. 2015, 3, 8. [CrossRef] [PubMed]

6. Krause, J.; Krause, S.; Arlinghaus, R.; Psorakis, I.; Roberts, S.; Rutz, C. Reality mining of animal social systems. Trends Ecol. Evol. 2013, 28, 541-551. [CrossRef] [PubMed]

7. Williams, H.J.; Taylor, L.A.; Benhamou, S.; Bijleveld, A.I.; Clay, T.A.; de Grissac, S.; Demsar, U.; English, H.M.; Franconi, N.; Gomez-Laich, A.; et al. Optimizing the use of biologgers for movement ecology research. J. Anim. Ecol. 2020, 89, 186-206. [CrossRef] [PubMed]

8. Bevanda, M.; Horning, N.; Reineking, B.; Heurich, M.; Wegmann, M.; Mueller, J. Adding structure to land cover-using fractional cover to study animal habitat use. Mov. Ecol. 2014, 2, 26. [CrossRef] [PubMed] 
9. Kuenzer, C.; Ottinger, M.; Wegmann, M.; Guo, H.; Wang, C.; Zhang, J.; Dech, S.; Wikelski, M. Earth observation satellite sensors for biodiversity monitoring: Potentials and bottlenecks. Int. J. Remote Sens. 2014, 35, 6599-6647. [CrossRef]

10. Pimm, S.L.; Alibhai, S.; Bergl, R.; Dehgan, A.; Giri, C.; Jewell, Z.; Joppa, L.; Kays, R.; Loarie, S. Emerging technologies to conserve biodiversity. Trends Ecol. Evol. 2015, 30, 685-696. [CrossRef]

11. Wetlands International. Waterbird Population Estimates. Wageningen, The Netherland Wetlands International, 2012. Available online: https:/ / www.wetlands.org/publications/waterbird-populations-estimates-fifth-edition/ (accessed on 8 October 2021).

12. Fujita, G.; Guan, H.L.; Ueta, M.; Goroshko, O.; Krever, V.; Ozaki, K.; Mita, N.; Higuchi, H. Comparing areas of suitable habitats along travelled and possible shortest routes in migration of White-naped Cranes Grus vipio in East Asia. Ibis 2004, 146, 461-474. [CrossRef]

13. Higuchi, H.; Ozaki, K.; Fijita, G.; Minton, J.; Ueta, M.; Soma, M.; Mita, N. Satellite tracking of White-naped crane migration and the importance of the Korean demilitarized zone. Conserv. Biol. 1996, 10, 806-812. [CrossRef]

14. Higuchi, H.; Pierre, J.P.; Krever, V.; Andronov, V.; Fujita, G.; Ozaki, K.; Goroshko, O.; Ueta, M.; Smirensky, S.; Mita, N. Using a remote technology in conservation: Satellite tracking White-naped Cranes in Russia and Asia. Conserv. Biol. 2004, 18, 136-147. [CrossRef]

15. Harris, J.; Mirande, C. A global overview of cranes: Status, threats and conservation priorities. Chin. Birds 2013, 4, 189-209. [CrossRef]

16. Gilbert, M.; Buuveibaatar, B.; Fine, A.E.; Jambal, L.; Strindberg, S. Declining breeding populations of White-naped Cranes in Eastern Mongolia, a ten-year update. Bird Conserv. Int. 2016, 26, 490-504. [CrossRef]

17. Harcourt, R.; Sequeira, A.M.M.; Zhang, X.L.; Roquet, F.; Komatsu, K.; Heupel, M.; McMahon, C.; Whoriskey, F.; Meekan, M.; Carroll, G.; et al. Animal-Borne Telemetry: An Integral Component of the Ocean Observing Toolkit. Front. Mar. Sci. $2019,6,326$. [CrossRef]

18. Sinnott, R.W. Virtues of the Haversine. Sky Telesc. 1984, 68, 159.

19. Hijmans, R.; Williams, E.; Vennes, C. Geosphere: Spherical trigonometry. R Package Version 1.5. Available online: https:/ / cran.r-project.org/web/packages/geosphere/geosphere.pdf (accessed on 8 October 2021).

20. van Wijk, R.E.; Kolzsch, A.; Kruckenberg, H.; Ebbinge, B.S.; Muskens, G.; Nolet, B.A. Individually tracked geese follow peaks of temperature acceleration during spring migration. Oikos 2012, 121, 655-664. [CrossRef]

21. Wang, X.; Cao, L.; Bysykatova, I.; Xu, Z.G.; Rozenfeld, S.; Jeong, W.; Vangeluwe, D.; Zhao, Y.L.; Xie, T.H.; Yi, K.P.; et al. The Far East taiga forest unrecognized inhospitable terrain for migrating Arctic-nesting waterbirds? Peerj 2018, 6, e4353. [CrossRef]

22. Deng, X.; Zhao, Q.; Fang, L.; Xu, Z.; Wang, X.; He, H.; Cao, L.; Fox, A.D. Spring migration duration exceeds that of autumn migration in Far East Asian Greater White-fronted Geese (Anser albifrons). Avian Res. 2019, 10, 19. [CrossRef]

23. Kolzsch, A.; Muskens, G.; Kruckenberg, H.; Glazov, P.; Weinzierl, R.; Nolet, B.A.; Wikelski, M. Towards a new understanding of migration timing: Slower spring than autumn migration in geese reflects different decision rules for stopover use and departure. Oikos 2016, 125, 1496-1507. [CrossRef]

24. Chen, Y.; Dobra, A. Measuring human activity spaces from GPS data with density ranking and summary curves. Ann. Appl. Stat. 2020, 14, 409-432. [CrossRef]

25. Barraquand, F.; Benhamou, S. animal movements in heterogeneous landscapes: Identifying profitable places and homogeneous movement bouts. Ecology 2008, 89, 3336-3348. [CrossRef] [PubMed]

26. Le Corre, M.; Dussault, C.; Côté, S.D. Detecting changes in the annual movements of terrestrial migratory species: Using the first-passage time to document the spring migration of caribou. Mov. Ecol. 2014, 2, 19. [CrossRef] [PubMed]

27. Edelhoff, H.; Signer, J.; Balkenhol, N. Path segmentation for beginners: An overview of current methods for detecting changes in animal movement patterns. Mov. Ecol. 2016, 4, 21. [CrossRef] [PubMed]

28. Lavielle, M. Using penalized contrasts for the change-point problem. Signal Process. 2005, 85, 1501-1510. [CrossRef]

29. Gong, P.; Liu, H.; Zhang, M.N.; Li, C.C.; Wang, J.; Huang, H.B.; Clinton, N.; Ji, L.Y.; Li, W.Y.; Bai, Y.Q.; et al. Stable classification with limited sample: Transferring a 30-m resolution sample set collected in 2015 to mapping 10-m resolution global land cover in 2017. Sci. Bull. 2019, 64, 370-373. [CrossRef]

30. Lang, X.; Gankhuyag Purev, O.; Oyunchimeg, T.; Dashdorj, K.; Baasansuren, E.; Amarkhuu, G.; Mi, C.; Guo, Y. Luan River upper reaches: The important stopover site of the white-naped crane (Grus vipio) western population. Biodivers. Sci. 2020, 28, $1213-1221$. [CrossRef]

31. Harris, J.; Liying, S.; Higuchi, H.; Ueta, M.; Zhengwang, Z.; Yanyun, Z.; Xijun, N. Migratory stopover and wintering locations in eastern China used by White-naped Cranes Grus vipio and Hooded Cranes, G. monacha, as determined by satellite tracking. Forktail 2000, 16, 93-100.

32. Sun, C.Z.; Zhen, L.; Wang, C.; Yan, B.Y.; Cao, X.C.; Wu, R.Z. Impacts of ecological restoration and human activities on habitat of overwintering migratory birds in the wetland of Poyang Lake, Jiangxi Province, China. J. Mt. Sci. 2015, 12, 1302-1314. [CrossRef]

33. Chen, Y.; Zhang, Y.; Cao, L.; de Boer, W.F.; Fox, A.D. Wintering Swan Geese maximize energy intake through substrate foraging depth when feeding on buried Vallisneria natans tubers. Avian Res. 2019, 10. [CrossRef]

34. Meng, F.; Li, H.; Wang, X.; Fang, L.; Li, X.; Cao, L.; Fox, A.D. Size matters: Wintering ducks stay longer and use fewer habitats on largest Chinese lakes. Avian Res 2019, 10. [CrossRef]

35. Wang, C.; Dong, B.; Zhu, M.; Huang, H.; Cui, Y.-h.; Gao, X.; Liu, L.-P. Habitat selection of wintering cranes (Gruidae) in typical lake wetland in the lower reaches of the Yangtze River, China. Environ. Sci. Pollut. Res. 2019, 26, 8266-8279. [CrossRef] 
36. Zhang, Y.; Cao, L.E.I.; Barter, M.; Fox, A.D.; Zhao, M.; Meng, F.; Shi, H.; Jiang, Y.; Zhu, W. Changing distribution and abundance of Swan Goose Anser cygnoides in the Yangtze River floodplain: The likely loss of a very important wintering site. Bird Conserv. Int. 2010, 21, 36-48. [CrossRef]

37. Lai, X.J.; Shankman, D.; Huber, C.; Yesou, H.; Huang, Q.; Jiang, J.H. Sand mining and increasing Poyang Lake's discharge ability: A reassessment of causes for lake decline in China. J. Hydrol. 2014, 519, 1698-1706. [CrossRef]

38. Guo, H.; Hu, Q.; Zhang, Q.; Feng, S. Effects of the Three Gorges Dam on Yangtze River flow and river interaction with Poyang Lake, China: 2003-2008. J. Hydrol. 2012, 416, 19-27. [CrossRef]

39. Mei, X.; Dai, Z.; Du, J.; Chen, J. Linkage between Three Gorges Dam impacts and the dramatic recessions in China's largest freshwater lake, Poyang Lake. Sci. Rep. 2015, 5, 18197. [CrossRef] [PubMed]

40. Zhang, Q.; Li, L.; Wang, Y.G.; Werner, A.D.; Xin, P.; Jiang, T.; Barry, D.A. Has the Three-Gorges Dam made the Poyang Lake wetlands wetter and drier? Geophys. Res. Lett. 2012, 39, L20402. [CrossRef]

41. Jiao, L. CHINA Scientists line up against Dam that would alter protected wetlands. Science 2009, 326, 508-509. [CrossRef] [PubMed]

42. An, A.; Cao, L.; Jia, Q.; Wang, X.; Zhu, Q.; Zhang, J.; Ye, X.; Gao, D. Changing abundance and distribution of the wintering swan goose Anser cygnoides in the Middle and Lower Yangtze River floodplain: An investigation combining a field survey with satellite telemetry. Sustainability 2019, 11, 1398. [CrossRef]

43. Aharon-Rotman, Y.; McEvoy, J.; Zheng, Z.J.; Yu, H.; Wang, X.; Si, Y.L.; Xu, Z.G.; Yuan, Z.; Jeong, W.; Cao, L.; et al. Water level affects availability of optimal feeding habitats for threatened migratory waterbirds. Ecol. Evol. 2017, 7, 10440-10450. [CrossRef]

44. Amano, T.; Szekely, T.; Koyama, K.; Amano, H.; Sutherland, W.J. A framework for monitoring the status of populations: An example from wader populations in the East Asian-Australasian flyway. Biol. Conserv. 2010, 143, 2238-2247. [CrossRef]

45. Martin, G.R.; Shaw, J.M. Bird collisions with power lines: Failing to see the way ahead? Biol. Conserv. 2010, 143, 2695-2702. [CrossRef]

46. Stehn, T.V.; Wassenich, T. Whooping crane collisions with power lines: An issue paper. Proc. North Am. Crane Workshop 2008, 10, 25-36.

47. Tacha, T.; Martin, D.; Endicott, C. Mortality of Sandhill Cranes associated with utility highlines in Texas. In Proceedings of the 1978 North American Crane Workshop, Rockport, TX, USA, 6-8 December 1979.

48. Swaddle, J.P.; Moseley, D.L.; Hinders, M.K.; Smith, E.P. A sonic net excludes birds from an airfield: Implications for reducing bird strike and crop losses. Ecol. Appl. 2016, 26, 339-345. [CrossRef] [PubMed]

49. van Gasteren, H.; Krijgsveld, K.L.; Klauke, N.; Leshem, Y.; Metz, I.C.; Skakuj, M.; Sorbi, S.; Schekler, I.; Shamoun-Baranes, J. Aeroecology meets aviation safety: Early warning systems in Europe and the Middle East prevent collisions between birds and aircraft. Ecography 2019, 42, 899-911. [CrossRef]

50. Blackwell, B.F.; Seamans, T.W.; Fernandez-Juricic, E.; Devault, T.L.; Outward, R.J. Avian responses to aircraft in an airport environment. J. Wildl. Manag. 2019, 83, 893-901. [CrossRef]

51. Shergalin, J.E.; Keskpaik, J.; Kuznetsov, G.A. The Common Crane with its migration conditions and as a hazard to aircraft in Estonia. In Crane Research and Protection in Europe; Prange, H., Ed.; Martin-Luther Universität: Halle-Wittenberg, Germany, 1995; pp. 165-169.

52. Navarrete, L.; Griffis-Kyle, K.L. Sandhill Crane collisions with wind turbines in Texas. In Proceedings of the Twelfth North American Crane Workshop, Grand Island, NE, USA, 13-16 March 2011; 2016; pp. 65-67.

53. BirdLife International. Species factsheet: Grus vipio. 2021. Available online: http:/ / www.birdlife.org (accessed on 30 August 2021).

54. Nilsson, C.; Klaassen, R.H.G.; Alerstam, T. Differences in speed and duration of bird migration between spring and autumn. Am. Nat. 2013, 181, 837-845. [CrossRef] [PubMed]

55. Zhao, M.; Christie, M.; Coleman, J.; Hassell, C.; Gosbell, K.; Lisovski, S.; Minton, C.; Klaassen, M. Time versus energy minimization migration strategy varies with body size and season in long-distance migratory shorebirds. Mov. Ecol. 2017, 5, 23. [CrossRef]

56. Benhamou, S. How to reliably estimate the tortuosity of an animal's path: Straightness, sinuosity, or fractal dimension? J. Theor. Biol. 2004, 229, 209-220. [CrossRef]

57. Batschelet, E. Circular Statistics in Biology. Technometrics 1981, 24, 336. 